\title{
Let us play together! Can play tutoring stimulate children's social pretend play level?
}

Journal of Early Childhood Research 2019, Vol. 17(3) 205-219

(C) The Author(s) 2019

Article reuse guidelines: sagepub.com/journals-permissions DOI: $10.1177 / 1476718 \times 19849248$ journals.sagepub.com/home/ecr

@SAGE

\section{Sonja Perren}

Thurgau University of Teacher Education, Switzerland; University of Konstanz, Germany

\section{Fabio Sticca}

Marie Meierhofer Children's Institute, Switzerland

\section{Barbara Weiss-Hanselmann and Carine Burkhardt Bossi}

Thurgau University of Teacher Education, Switzerland

\begin{abstract}
Social pretend play may have a positive impact on children's social development because it involves positive peer interactions and challenges their social-cognitive abilities. The current study aimed to investigate whether variations in play tutors' active support and play management are associated with variations in children's social pretend play level in the context of a pretend play tutoring intervention. Moreover, the moderating role of children's social skills (cooperative behaviour and sociability) was examined. In total, 50 children from eight playgroups participated in the study $(50 \%$ females, mean age at $\mathrm{TI}=46.6$ months, $\mathrm{SD}=4.3)$. Six play tutoring sessions took place during normal playgroup sessions (30-40 minutes each). Both the play tutors' active support and play management and the children's social pretend play were videotaped and rated for each 10-minute interval. Furthermore, teachers rated children's social skills before the intervention. The study showed that active support - but not play management - was positively associated with children's social pretend play level. Furthermore, children's sociability positively predicted children's social pretend play level during the intervention and also intensified the positive effect of active support on children's social pretend play level. In contrast, children's cooperative behaviour was not significantly associated with their social pretend play level. These results suggest that play tutoring in a group setting needs to be tailored to children's needs and should actively aim to include withdrawn children, so that they can also profit more strongly from the intervention.
\end{abstract}

\section{Keywords}

intervention, play tutoring, social pretend play, social skills

\section{Corresponding author:}

Sonja Perren, Development and Education in Early Childhood, Thurgau University of Teacher Education, Bärenstrasse 38, 8280 Kreuzlingen, Switzerland.

Email: sonja.perren@uni-konstanz.de 
Social pretend play allows children to create different make-believe scenarios in which they can use pretence and symbolism to take on different roles and perspectives. Children can thereby experiment with themselves, their peers, adults, and their environment, which is an ideal way of developing social-cognitive skills and social skills (Bergen, 2013; Smith, 2010). Social pretend play may have a positive impact on children's social development because it involves positive peer interactions (e.g. sharing, asserting, waiting, and role-taking) and also because it challenges their social-cognitive abilities such as Theory of Mind (ToM) and understanding of emotions (Lillard et al., 2013). Thus, social pretend play is an important aspect of child development.

Given the potential of social pretend play, how can social pretend play be fostered? Play tutoring might be an effective way to improve children's social pretend play level (Bodrova, 2008; Christie, 1983; Craig-Unkefer and Kaiser, 2003; Gmitrova, 2013; Smilansky, 1968; Smilansky and Shefatya, 1990). However, play tutoring is usually conducted in peer group settings and requires a certain level of children's social skills in order to be effectively implemented. This study aimed to investigate whether play tutoring can stimulate children's social pretend play level and whether all children profit from play tutoring in the same way. We specifically addressed the question of how (which strategies) and for whom (differential effects) play tutoring has a positive impact.

\section{Development of social pretend play}

Children start showing pretence activities in their play at around 15 months of age (Smith, 2010). In contrast to other play activities, the symbolic function ( 'as-if' orientation) is essential for pretend play. On the symbolic level, the development of pretend play follows a normative pattern that goes from decentration, a shift from self to other as agent, to decontextualization, a more frequent use of imaginary objects and actions in pretence, to integration, where several pretend acts form entire sequences and narratives (Hauser, 2013). Roots of (social) pretend play can be found in the early interaction between children and parents. Later, peers become preferred social pretend play partners. Elkonin (2005) showed that the level and duration of pretend play tends to increase when children start playing with peers. On the interaction level, pretend play develops from single to parallel, associative, and finally cooperative play (Elkonin, 2005). Opportunities for peer interaction and thus for social pretend play tend to increase around the age of 3 years, when many children start attending some form of preschool setting. For example, in Switzerland, children start attending educational playgroups at this age.

Besides the normative developmental patterns described above, large interindividual differences in children's propensity for engagement in (social) pretend play and their actual level of such play can be observed from early on. Bodrova et al. (2013) proposed that the quality of play (i.e. level of social pretend play) might be critical for the developmental benefit of pretend play. Promoting children's social pretend play level (e.g. through play tutoring) might therefore be an educational pathway to improve children's social development.

\section{Promoting children's social pretend play}

Smilansky's (1968) work on the effect of various role-play interventions for children from socially disadvantaged backgrounds, inspired numerous studies on the association between pretend play and development. Based on Smilansky and Shefatya (1990), most pretend play studies used some kind of play tutoring as a training approach, distinguishing between outside intervention (i.e. adults assume an outsider position, make comments, and ask questions to maintain and improve the pretend play) and play participation (i.e. adult plays along, provides new ideas and models play behaviour). These two approaches have also been combined (Berk et al., 2006; Christie, 1983; 
Craig-Unkefer and Kaiser, 2003; Gmitrova, 2013). For instance, Gmitrova (2013) used a combined approach in a study of 368 three- to six-year-olds, using a 3-day intervention with decreasing degrees of adult involvement ranging from play participation to outside intervention. The authors showed that children's pretend play was linked to the degree of adult involvement and concluded that active and participatory play tutoring promoted children's level of social pretend play. Other pretend play training approaches engage children in pretend or fantasy play through drama lessons, story and fairy-tale enactments (Baumer et al., 2005; Qu et al., 2015), or narrative methods (e.g. Nicolopoulou et al., 2010). These approaches are more strongly teacher-directed and structured than play tutoring.

In contrast to teacher-directed approaches, child-centred play tutoring approaches are able to match the individual developmental needs of each child: A play tutor suggests an activity (e.g. a social pretend play theme) to a group of children who can then choose whether, how long, and how actively they want to engage themselves. Children are also able to form small groups and follow their own scripts. The play tutor's task is to apply a portfolio of play tutoring strategies such as prompting, modelling, and naturalistic instruction (e.g. arranging the learning environment) that are individualized and build upon children's interest (Lang et al., 2009). This approach is a mixture of teacher-led and child-initiated pretend play training (Gmitrová and Gmitrov, 2003). The training approach that we propose for this study is in line with the current understanding of effective early childhood education: child-centred educational practices are characterized by an understanding of effective promotion of children's learning and development that is consistent with children's individual needs and developmental level (Copple and Bredekamp, 2010). Child-centred educational approaches correspond to current moves in early childhood education in Switzerland (Perren et al., 2017).

\section{The current study}

In this study, we investigated the impact of play tutors' behaviour (active support and play management) on children's social pretend play level. Active support is characterized by a high level of adult involvement in children's play through modelling, prompting, verbalizations and following children's play ideas. In contrast, play management is understood as giving organizational inputs or reacting to disturbances. In line with empirical findings (e.g. Gmitrova, 2013), we hypothesize that active support stimulates children's social pretend play level, while no specific hypotheses were constructed for play management.

A total of six intervention sessions with time intervals on 1 week were carried out in the context of playgroup sessions lasting up to 40 minutes. Both play tutors' and children's behaviour were videotaped during each session and rated for each cycle of 10 minutes. This strategy resulted in variation of tutors' and children's behaviour both across the six sessions and within each single session (i.e. across cycles of each session). We thus took advantage of this variation to analyse whether tutors' behaviour is systematically linked to children's behaviour, thereby approaching the investigation of a causal relationship. For this, we used a state-trait modelling approach which analyses whether active support and/or play management are predictive of children's pretend play level in a specific cycle of 10 minutes (i.e. state), taking into account differences between children in their pretend play level (i.e. trait).

Social pretend play interventions are usually conducted in the context of peer groups and require a certain level of children's social skills to be practicable. Children are required to participate and to cooperate in a peer group activity in which they also encounter new adults (i.e. play tutor). This setting might be more favourable for those children who are able to cope with its conditions. The question therefore arises as to whether children's social skills moderate the intervention effects. We specifically explored whether children's sociability (i.e. ability to initiate and engage in social 
interactions) and cooperative behaviour (i.e. ability to follow peers' play ideas and play tutors' proposed activities) strengthen the effects of play tutoring on children's social pretend play level. Thus, we examined whether children's social skills are linked to their pretend play level across the six interventions (i.e. trait) and whether social skills moderated the associations between play tutoring and social pretend play within each cycle of 10 minutes (i.e. state level).

Moreover, we investigated whether there were systematic changes in children's behaviour related to time (across the six interventions sessions) and cycle (within an intervention session). We expected that social pretend play level would increase across the six intervention sessions. Besides the play sequences, the intervention sessions included a planning and reflection sequence of a few minutes at the beginning and end of the session, respectively. As children naturally have fewer opportunities to play during planning and reflection, the role of the sequence (i.e. planning, play, reflection as coded for each cycle of 10 minutes) was controlled for in the analyses, so no confounding with actual change in children's behaviour would occur. Herein, it must be noted that more than one type of sequence could be present within a single cycle of 10 minutes.

In addition to the above-mentioned predictor variables, we included age, gender and ToM skills as control variables in the analyses, as gender differences in the type of play and in the activities and themes of choice were also found (Power, 2011). Furthermore, studies indicate that there are significant associations between children's ToM skills and their pretend play level (Lillard et al., 2013; Qu et al., 2015).

\section{Method}

\section{Study design}

Playgroups participated in a total of six play tutoring intervention sessions. Playgroup educators completed a questionnaire on children's social behaviour, and children were tested before the first intervention session. Interventions were videotaped, and children's and play tutors' behaviours were rated using standardized manuals.

\section{Recruitment}

Eight playgroups were recruited for study participation. In Switzerland, playgroups are educational institutions open to children over 3 years of age. The aim is to give children the opportunity to play with peers under the supervision of a trained playgroup educator. Playgroup sessions usually take place once or twice a week and last 2-3 hours each. Children usually start in August of the year before they attend mandatory kindergarten and attend the same playgroup for 1 year.

In a first step of the recruitment procedure, playgroup educators were asked to participate in the study. Parents were then informed about the study in writing and provided written consent for their child's participation. Parents of non-participating children were informed that although no individual data would be collected (including coding from the videos), their children might still appear on the videos if they attended the playgroup on intervention days.

Children were tested by trained graduate students (pursuing an early childhood education or psychology degree) who were sensitized to children's decision-making rights and capabilities. Children were given the opportunity to refuse or stop their individual tests at any time without any consequences. Children were also informed about the study in an age-appropriate way (e.g. we explained the rationale of the use of the video camera in simple language). Playgroup educators received appropriate financial compensation and children were given a children's book as a present. 


\section{Participants}

A total of 52 children were given permission for study participation (i.e. tests and observations). Two children were excluded from the analyses because one had severe language difficulties, and the other did not participate in the intervention sessions. Ten children were not allowed to be tested or observed but did participate in the intervention sessions. Six to eight children participated in each group. Children were between 34 and 56 months of age $(\mathrm{M}=46.6, \mathrm{SD}=4.31)$ and had attended the playgroup for an average of 28 weeks $(S D=19.4)$. Eighty-one per cent of children spoke German as their family language. Not all children were present in each intervention sessions (e.g. due to illness). The number of children with valid data therefore varied between 36 and 48 per session.

\section{Assessment of social skills}

Social skills were assessed during the pretest before the intervention. Playgroup educators completed a questionnaire on children's social behaviour (Perren, 2007; Perren et al., 2012). For this study, we used the subscales sociability and cooperative behaviour with peers and adults. All items were rated on a 3 -point scale $(1=$ not at all true, $2=$ partially true and $3=$ definitely true $)$. The sociability subscale, covering propensity to participate in social interactions, consisted of four items (e.g. Converses with peers easily, $\alpha=.68$ ). The cooperation with peers subscale contained three items (e.g. Compromises in conflicts with peers, $\alpha=.69$ ), and the cooperation with adults scale also encompassed of three items (e.g. Follows instructions by adults, $\alpha=.80$ ). The two cooperation subscales were strongly correlated $(r=.54)$ and were thus combined into a mean score for this study $(\alpha=.82)$.

\section{Assessment of ToM skills}

Children were tested in an individual setting before the intervention. ToM skills were tested using the German version of the Extended Theory of Mind Scale (EToM; Henning et al., 2012). The EToM is a well-validated test consisting of multiple tasks of increasing difficulty tapping into different developmental stages of ToM (Kristen et al., 2006). For this study of 3- and 4-year-old children, only the first four tasks were selected: diverse desire, diverse beliefs, knowledge access, and contents false belief. The sum of correct responses was used as ToM score for the analyses.

\section{Assessment of children's social pretend play level}

A standardized manual was developed by our research group to assess children's social pretend play level. The manual is based on characteristic features and steps of the normative development of pretend play (Hauser, 2013; Smilansky, 1968; Smith, 2010). It consists of the following categories and response options: Decentration $(0=$ no decentration, $1=$ self-related play, $2=$ object-related play, $3=$ other-related play); Decontextualization $(0=$ no decontextualization, $1=$ imitation, $2=$ object substitution, $3=$ fantasy transformation); Role-taking $(0=$ no role-taking, $1=$ role-taking without role-conforming behaviour, 2 =role-taking with some role-conforming behaviour, $3=$ sustained role-taking and role-conformity) and Sequencing $(0=$ no sequencing, $1=$ limited script elements, 2 =several actions without a script, $3=$ flexible application of a script). The scale's internal consistency is $\alpha=.94$.

Individual child behaviour was rated for each 10-minute cycle, resulting in up to 24 cycles (i.e. 6 sessions of 4 cycles each) per child. For each category, the highest observed level was rated. To ensure objective ratings, an extensive training procedure (including double ratings and consistency 
ratings) was conducted. Furthermore, the reliability of the rating scales was assessed by a randomly selected double coding of 20 per cent of all videos. Due to the varying number of cycles in each video (3-4), this resulted in a double coding of 18 per cent of all observation cycles. The inter-rater reliability was high: intra-class correlations for all categories were above .90 .

\section{Intervention: social pretend play tutoring}

Playgroups participated in a total of six intervention sessions during normal playgroup sessions. These interventions were carried out once per week for six consecutive weeks, each lasting approximately 30-40 minutes. Our social pretend play tutoring approach was inspired by the work by Craig-Unkefer and Kaiser (2003). A trained play tutor joined the playgroup and proposed a specific pretend play activity (firefighters in Sessions 1-3 and hospital in Sessions 4-6) for the entire playgroup. After the introduction to the whole group, child participation in the activity was voluntary.

The play tutor brought a standardized set of equipment to be used for the pretend play activity (e.g. helmets and a hose, or bandages and white coats). During the planning sequence, children were briefly introduced to the topic of the pretend play activity, and the equipment was distributed as fairly as possible. Thereafter, children were free to develop pretend play scenarios. In the subsequent play sequence, the play tutor would solicit positive peer interactions and symbolic representations using a specific set of prompts. These prompts aimed to involve the children in the activity, keep the story alive and have the children play along for about 30 minutes. The activity ended with a short reflection sequence with the whole group, resulting in a session of around 40 minutes total.

We standardized variations in play tutors' involvement across the six intervention sessions. The first session of each play theme (Sessions 1 and 4) was characterized by low adult involvement (outside intervention), creating an exploratory climate among the children. In contrast, the second session of each play theme (Sessions 2 and 5) was characterized by the tutor's active participation and high involvement (inside intervention). The final session of each play theme (Sessions 3 and 6) was characterized by the partial withdrawal of the play tutor (mixed inside and outside intervention). Besides natural variations, this strategy resulted in variations in play tutors' strategies both within each session and across the six sessions.

All interventions were videotaped by a research assistant. Playgroup educators were in the room without engagement in the activity. They were available for children who opted to leave the ongoing intervention activity.

\section{Assessment of play tutoring strategies}

The behavioural strategies of the play tutors were videotaped during the intervention. The behaviour was rated over 10-minute cycles of the intervention, resulting in 24 cycles per playgroup (6 sessions of 4 intervals each). The coding manual was developed by our research group and was based on behavioural strategies suggested by other studies to promote children's social pretend play (Bodrova et al., 2013; Gmitrova, 2013; Lang et al., 2009). The measures consist of two scales: active support and play management. A set of relevant observable indicators was defined for each strategy. The frequency and intensity of observed behaviours were rated on a 5-point Likert-type scale $(1=$ none of the indicators was observed, $2=$ one indicator was observed a few times, $3=$ half or more of the indicators were observed several times, $4=$ most indicators were observed several times and $5=$ all indicators were present and frequently observed).

The scale active support consisted of four play tutoring strategies: prompting (using verbal or nonverbal prompts to initiate interactions or pretend use of objects), verbalization (use of questioning and language modelling techniques), modelling (playing along and demonstrating play actions and 


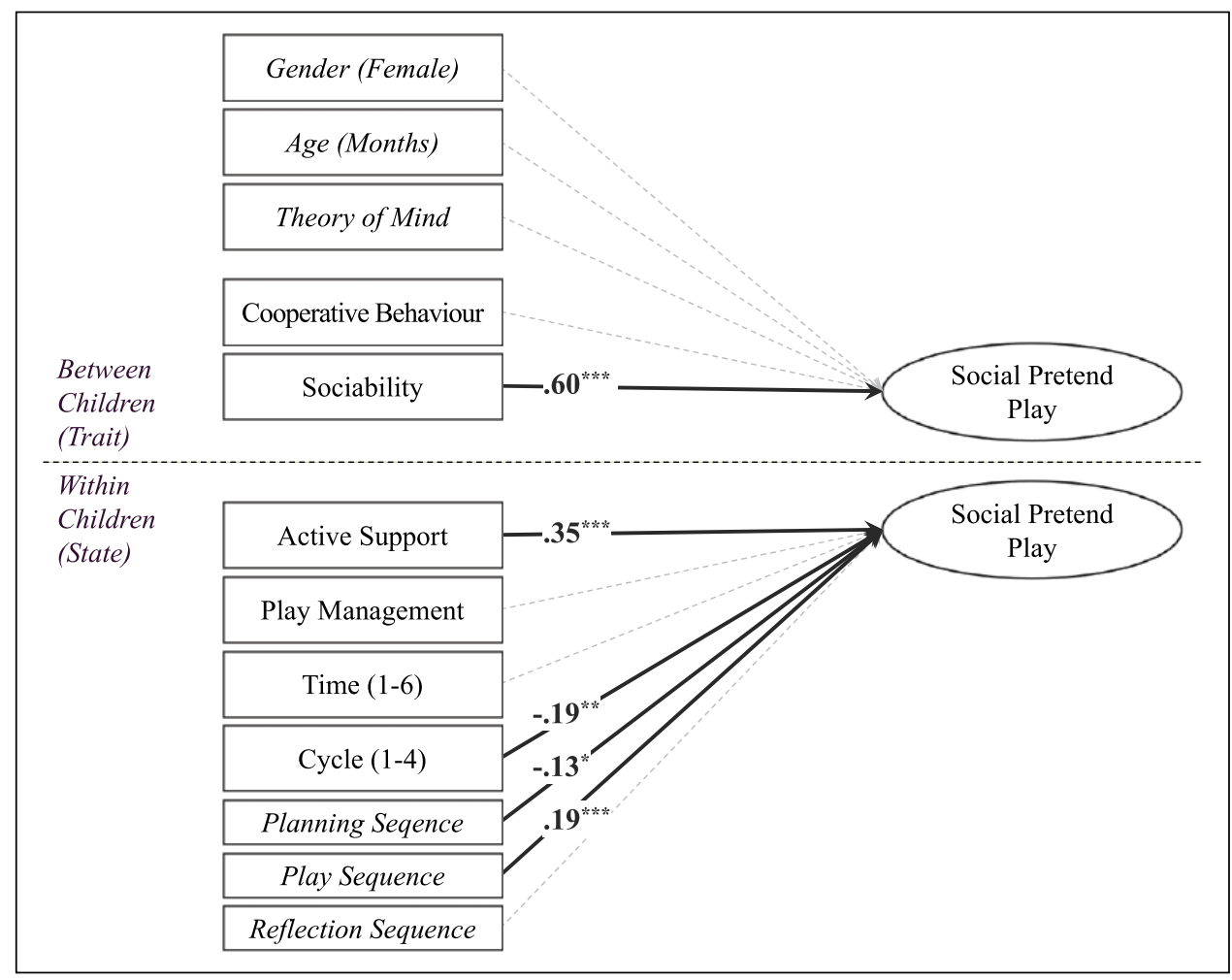

Figure I. Standardized results of the latent state-trait multilevel model without random effects (main effects model). Only significant effects are displayed. Control variables are shown in italic. Model parameters that are not central to the research question are not displayed (e.g. correlations between exogenous variables).

interactions) and following child interests (following children's suggestions and play ideas). The scale's internal consistency was $\alpha=.73$. The category play management included three different indicators: regulation and reactions to disturbances, organizational inputs, and introduction of materials.

To ensure objective ratings, an extensive training procedure (including double ratings and consistency ratings) was conducted. Furthermore, the reliability of the rating scales was assessed by a randomly selected double coding of 20 per cent of all videos. Due to the varying number of cycles in each video (3-4), this resulted in a double coding of 14 per cent of all observation cycles. Interrater reliability was found to be moderate to high: the intra-class correlations for the overall scale active support was .86, while for play management, it was .80 .

\section{Technical description of the multilevel analysis strategy}

A state-trait multilevel model was used to model the impact of social pretend play tutoring on children's level of social pretend play at both the within-child level (state) and the between-children level (trait). Two different models were computed, Model 1 with main effects only (see Figure 1) and Model 2 investigating differential effects (see Figure 2).

First, social pretend play was modelled as a latent variable with four indicators (i.e. decentration, decontextualization, role-taking and sequencing) both at the within-child level and at the 


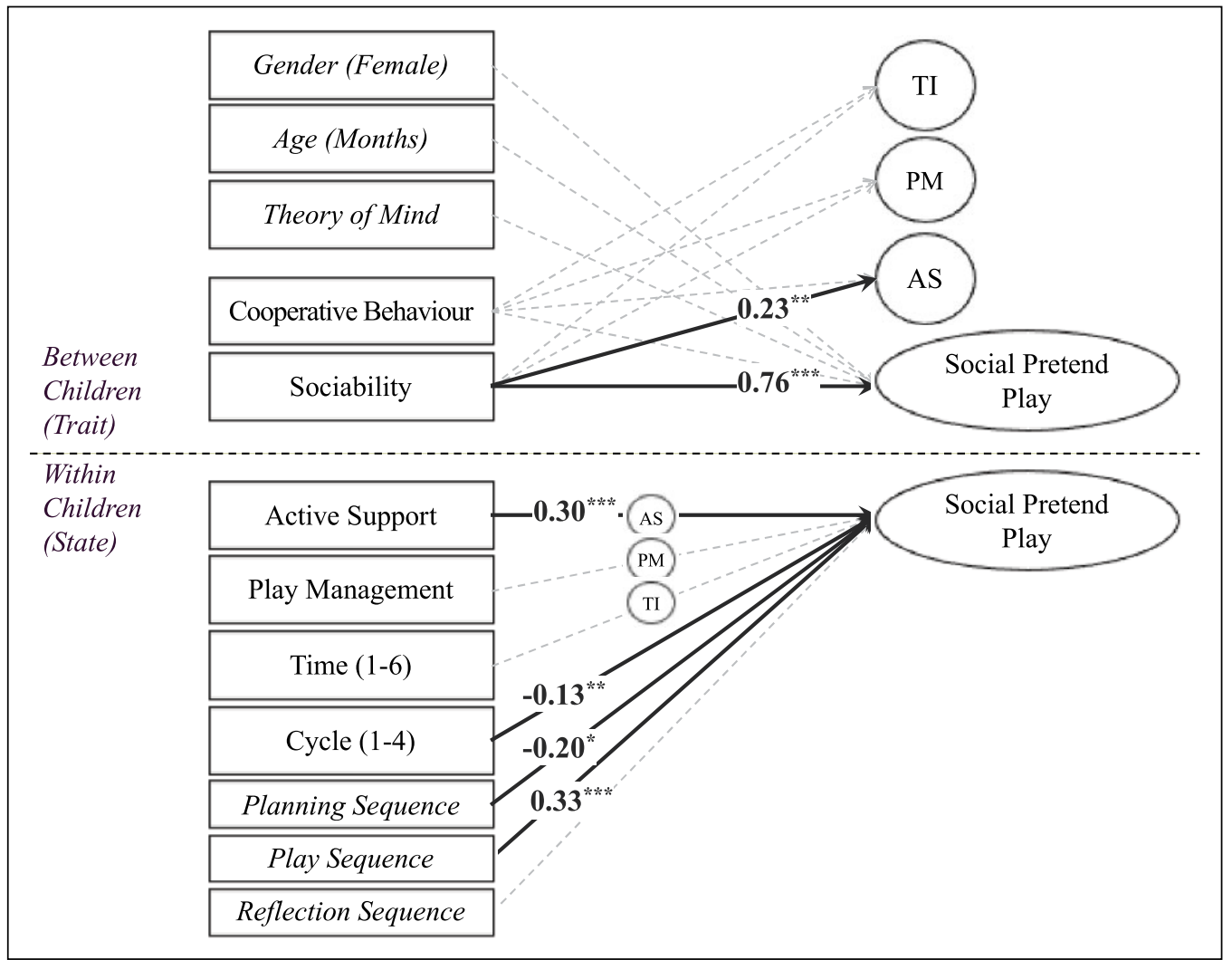

Figure 2. Unstandardized results of the doubly latent state-trait multilevel model with random effects (differential effects model). Random effects are indicated by a circle on the respective arrow on the withinchild level. Only significant effects are displayed. Model parameters that are not central to the research question are not displayed (e.g. correlations between exogenous variables).

TI: Time; PM: Play Management; AS: Active Support.

between-children level, thus resulting in a doubly latent model (i.e. the same variable is modelled as a latent variable on both the within and the between level. In the same model, the effects of time and cycle on social pretend play were modelled as fixed effects on the within-child level (Sticca et al., 2017).

In a second step, various predictors were introduced at both the within-child level and betweenchildren level. More precisely, active support (prompting, verbalization, modelling and following child interests) and play management were added as manifest predictors of social pretend play at the within-child level. Furthermore, sociability and cooperative behaviour were added to the model as manifest predictors of the random intercept of social pretend play at the between-children level.

The control variables were modelled as follows: ToM skills, gender $(0=$ male $;=$ female $)$, and children's age in months were added to the model as manifest predictors of the random intercept of social pretend play at the between-children level. Furthermore, three not mutually exclusive dummy variables for the sequence of the intervention (planning, play and reflection sequence) were added as manifest predictors of social pretend play at the within-child level.

A second model (differential effects model, Figure 2) was computed to identify differential effects of play tutoring on social pretend play. For this, the slopes of active support, play 
management and time on social pretend play were additionally modelled as random effects, and on the between-children level, sociability and cooperative behaviour were modelled as predictors of all three random effects (i.e. cross-level interactions).

The effect coding method was used to identify all latent variables (Little, 2013). All predictors were grand mean centred before being introduced into the model, except for the binary variables. The resulting model showed an acceptable fit to the data $\left(\chi^{2}=169.651 ; \mathrm{df}=53\right.$; comparative fit index $(\mathrm{CFI})=.92$; root mean square error approximation $(\mathrm{RMSEA})=.05 ; \mathrm{SRMR}_{\mathrm{within}}=.04$; $\left.\mathrm{SRMR}_{\text {between }}=.11\right)$. The acceptable model fit indicates that the model represents an acceptable simplification of the data's complexity and that results are interpretable.

\section{Results}

Results of the latent state-trait multilevel model without cross-level interactions are shown in Figure 1 (main effect model). On the within-child level, active support positively predicted social pretend play $(\beta=.35 ; p<.001)$. Thus, more active support was linked to higher scores in social pretend play in a given cycle. In contrast, play management was not found to have a significant effect on children's social pretend play level. Time did not have a significant effect. However, the cycle was negatively linked to social pretend play $(\beta=-.19 ; p<.01)$, suggesting that the quality of pretend play tended to fade out during each session. Finally, lower social pretend play levels were found during planning sequences $(\beta=-.13 ; p<.05)$, while higher scores were found in the play sequences $(\beta=.19 ; p<.001)$, which represents the decreased and increased possibility for social pretend play, respectively.

On the between-children level, sociability was found to have a positive effect on social pretend play $(\beta=.60 ; p<.001)$, while cooperative behaviour $(\beta=-.14 ; p=.19)$, female gender $(\beta=.06$; $p=.66)$, age $(\beta=-.01 ; p=.96)$ and ToM skills $(\beta=.03 ; p=.85)$ were not found to be significant predictors when controlling for the other predictors. Accordingly, these between-children level results suggested that children with higher scores on sociability tended also to have higher scores for social pretend play, while all other between-children level predictors did not contribute significantly to the prediction of social pretend play over and above children's sociability. A total of 25 per cent of the variance of social pretend play could be explained on the within-child level, while 38 per cent could be explained on the between-children level.

Results of the model with cross-level interactions can be found in Figure 2 (differential effects

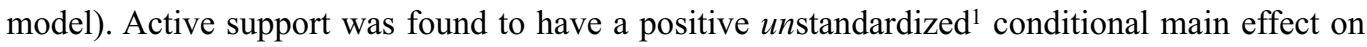
social pretend play level on the within-child level $(B=0.30 ; p<.001)$. Sociability also had a positive conditional main effect on social pretend play level on the between-children level $(B=0.76$; $p<.001)$. Regarding the cross-level interaction, sociability was found to positively moderate the association between active support and social pretend play level $(B=0.23 ; p<.01)$. Figure 3 shows the conditional effects of active support on social pretend play level for different levels of sociability. For children with average scores of sociability, situations with more active support were linked to higher scores in social pretend play level. Conversely, in situations with average active support, children's sociability was linked to higher scores of social pretend play level. Furthermore, the already positive conditional main effect of active support on the social pretend play level (see above) became more positive with increasing scores of sociability (i.e. cross-level interaction).

Results showed that cooperative behaviour did not have a significant conditional main effect on social pretend play at the within-child level $(B=-0.39 ; p=.13)$ and did not moderate the association between active support and social pretend play level $(B=-0.14 ; p=.06)$. Play management was not found to have a significant conditional main effect on social pretend play level at the within-child level $(B=-0.05 ; p=.07)$, and neither sociability $(B=0.05 ; p=.31)$ nor cooperative behaviour 


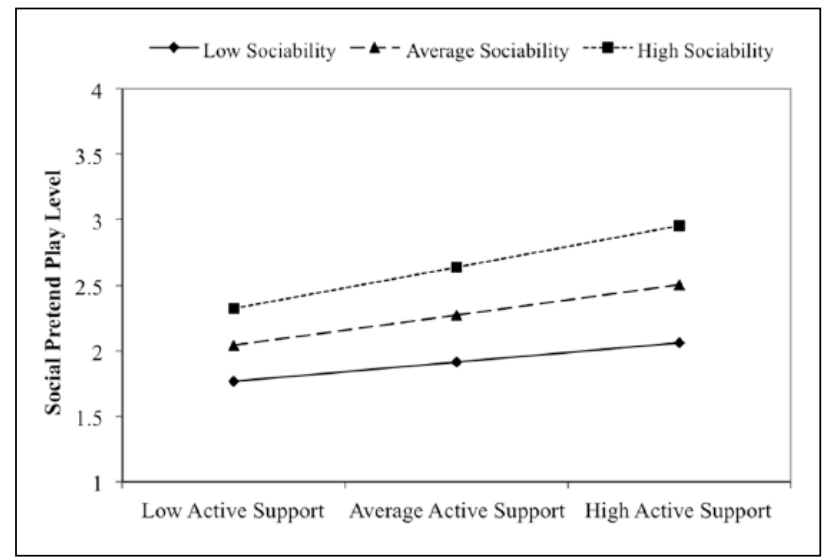

Figure 3. Graph of the interaction between active support and sociability in their effect on social pretend play level.

$(B=-0.07 ; p=.39)$ was found to moderate this effect. In other words, play management neither solicited nor hindered children's level of social pretend play over and above the effects of the other variables in the model. Furthermore, time was not found to have a significant conditional main effect on social pretend play at the within-child level $(B=-0.01 ; p=.86)$, and neither sociability $(B=-0.05$; $p=.37)$ nor cooperative behaviour $(B=0.08 ; p=.26)$ was found to moderate this effect. Thus, there was no average increase in social pretend play across time, and neither sociability nor cooperative behaviour was found to moderate this non-significant effect. However, the negative effects of cycle $(B=-0.13 ; p<.01)$ and of planning sequence $(B=-0.20 ; p<.05)$, as well as the positive effect of the play sequence $(B=0.33 ; p<.001)$ and the non-significant effect of the reflection sequence $(B=-0.05$; $p=.58)$, were again found. As for the remaining predictors of the random intercept on the betweenchildren level, ToM skills $(B=0.03 ; p=.79)$, gender $(B=-0.01 ; p=.63)$, and age $(B=0.09 ; p=.71)$ were not found to have significant effects on children's social pretend play level.

\section{Discussion}

This study investigated the effect of different play tutoring strategies, namely, active support and play management, on 50 three- to four-year-old children's social pretend play level. The analyses showed that the extent of active support provided by the play tutor through active play participation was positively linked to the level of social pretend play that children show in a given situation. The effect of active support was stronger in highly sociable children than in less sociable ones. Accordingly, these results indicate that children's level of social pretend play can effectively be enhanced through active support strategies in a playgroup context. However, it might be challenging to stimulate social pretend play activities in socially withdrawn children in play tutoring sessions.

\section{The impact of play tutoring on social pretend play level}

The multilevel analyses showed that higher levels of active support are associated with higher levels of children's social pretend play within sessions. This effect was shown on the within-child level, that is, variations in play tutor behaviour are systematically associated with situational 
variations of children's social pretend play level. In line with our hypotheses, play tutors were thus shown to actively stimulate children's social pretend play in specific situations.

However, the non-significant time effect indicated that there was no sustainable increase in social pretend play level over the six intervention sessions spanning 6 to 7 weeks. These seemingly conflicting results might indicate that the impact of tutoring is merely a scaffolding effect: children show a higher level of social pretend play when the play tutor actively plays with them, and their level of social pretend play drops as soon as the active support decreases. Therefore, the situational increase in children's social pretend play level does not transfer into a stable or sustainable increase within the 6 to 7 weeks of the intervention. The non-significant time effects might also be due to an insufficient fit between the tutor's active support and individual children's need for support. For example, Trawick-Smith and Dziurgot (2011) showed that direct play tutoring might have a negative effect on children's play when children have a low need for support. Future studies should therefore include measures of children's level of social pretend play in situations without adult support and analyse the potentially moderating role of children's baseline level of social pretend play.

An explanation for the parallel oscillations between play tutors' and children's behaviours lies in the play context that was created during the interventions. Having an adult propose a play topic, provide appealing material, give play ideas and play along was certainly not an everyday experience for the children in our sample. Therefore, children were following the adults' lead during the interventions and expected the adult to keep on leading the play. Accordingly, there was no need for children to do much planning, as the play tutor did the planning for the whole group. The very low levels of planning observed support this explanation. The low level of planning might also be due to children's age, as this skill only starts to develop from the age of 3 to 4 years (Hauser, 2013).

In sum, the pattern of results on the short-term and long-term effects of play tutoring on children's social pretend play level seems plausible, especially considering the low intensity and duration of the intervention. One aspect of play tutoring that could not be evaluated in the context of this study is whether there were any transfer effects to other settings and play situations and whether children use the acquired skills in new settings. For instance, over time children who experienced more play tutoring might show more social pretend play in normal group activities or at home and in other private and/or public settings. This lagged longitudinal impact might also be present in children who were only observers during the play tutoring session. Future studies should examine how play tutoring influences children's development of social pretend play, and whether any transfer effects to similar play situations occur.

Our study also revealed differential intervention effects. On one hand, children who were rated as being sociable (e.g. outgoing in group situations) by their playgroup educators were more positively affected by the play tutors' behaviour. It seems plausible that more sociable children found it easier to participate in this highly social kind of play and therefore participated more actively in the intervention. On the other hand, we found no significant association between cooperative behaviour and children's social pretend play level. Children whose educators rated them as being more cooperative in peer and adult interactions did not show higher levels of social pretend play than their peers who were reported to be less sociable. This finding is in line with our child-centred educational approach, where children are expected to take on an active role. On the positive side, these findings suggest that play tutoring, and active support in particular, have beneficial effects on children's social pretend play. However, the specific attributes of the interventions carried out created a social situation that favoured more sociable children in terms of potential for increased social pretend play levels. Thus, on the negative side, enhancing less sociable children's level of social pretend play might be a hard task with this specific kind of intervention, indicating the need for other forms of play that might benefit these children as well.

In contrast to active support, play management was not significantly associated with children's social pretend play level. This is a key finding, as play management subsumes behaviours that are 
frequently displayed by educators attempting to guide children's play such as assuming an outside position, organizing and giving inputs, and responding to disturbances. Our study shows that taking an observational and reactive role is not instrumental as far as increasing children's pretend play level is concerned. This non-significant association might also be related to the heterogeneous indicators of this subscale. Organizational inputs might increase children's social pretend play level, but behavioural regulation might inhibit children's play.

In addition to the main effect of active support, we also found differences between the play sequences. As might be expected, children show a lower social pretend play level in sequences with planning and reflection sequences than in play sequences. The effects reported above were controlled for these play sequence effects. We also found that social pretend play level decreased over the course of one session. This might indicate that after 30 minutes' play, children start to disengage from the activity. Thus, the chosen play duration of 30-40 minutes seemed appropriate.

\section{Inter-individual differences in social pretend play level}

In addition to the intervention effects, we also investigated whether children's social skills could predict the social pretend play level shown during the interventions. Sociability was the only social skill to reveal a positive association with the level of social pretend play, while cooperative behaviour did not. As discussed above, the peer group setting of the intervention seems to favour highly sociable children. Sociability also had a reinforcing effect. This indicates that sociable children have a higher level of social skills and also profit more from the intervention. Therefore, play tutoring did not have a compensatory effect for children with lower social skills but instead promoted children already at a higher level. To promote children's social development through social pretend play tutoring, the intervention should be adapted, so that it is better suited for shy children as well, for example, through explicit active encouragement to engage in peer play (Grady and Karraker, 2014).

Cooperative behaviour was not significantly associated with children's social pretend play level. This indicates that social pretend play requires a certain level of proactive social behaviour; just being cooperative and obedient and following rules does not imply a better play quality. This is partly in contrast to assumptions by Bodrova et al. (2013), who stated that complying with the group-defined rules is a sign of high pretend play level. They conclude that children improve their behavioural self-regulation due to this feature of role play. Cooperating with the group and adhering to group rules within the play setting might be necessary to engage in role play (Smilansky, 1968; Vygotsky, 1978), but our results indicate that being a cooperative child in the everyday context is not sufficient to show high levels of social pretend play in a strongly social setting such as the one created in our intervention.

In contrast to previous results (Lillard et al., 2013; Qu et al., 2015), ToM skills were not related to social pretend play level in this study. In our guided peer group setting, a high level of socialcognitive skills does not seem to be a prerequisite for advanced pretend play. This indicates that children can also show a higher quality of social pretend play through imitating play tutors' or other children's behaviour. We found no age or gender effects on children's social pretend play level; the non-significant gender effect suggests that girls were similarly motivated to participate in a stereotypically more masculine play topic such as being a firefighter.

\section{Strengths and limitations, and implications for further research}

Our study has a number of strengths and limitations. The longitudinal intervention design using mixed methods is certainly a strength of the study. However, we only collected pre-intervention data. We were thus unable to investigate changes in children's social or social-cognitive skills over 
the course of the study. Future studies should adopt a controlled intervention design with pre- and post-test measures to validate the intervention effects and to see whether we can observe transfer effects. However, the interindividual approach created variability in the exposure to play tutoring within each child, thereby allowing us to shed light on the within-person associations at hand. This approach can be considered as a natural form of experiment. The data were analysed using stateof-the-art statistical methods that allowed us to analyse both intra- and interindividual variations in social pretend play, play tutoring and child characteristics, as well as their interplay. We developed our own coding manuals (based on theoretical assumptions and previous literature). Appropriate inter-rater reliability was demonstrated for ratings of both play tutor's and children's behaviour. Confirmatory factor analyses also demonstrated good factorial validity. The rating of children's social pretend play level also has a strong theoretical foundation, as it is oriented towards the developmental steps of pretend play. Furthermore, our play tutoring intervention was conducted in a natural setting, and with naturally occurring peer groups, giving it high external validity.

In sum, our study shows play tutoring can strongly stimulate children's social pretend play level through modelling and prompting. The play tutor's role is both significant and challenging during the pretend play sessions. The challenge is to arrange a conducive and stimulating play situation to initiate learning and developmental processes for everybody. The play tutor needs to be active in providing appropriate prompts and play ideas for the group, while also needing time to observe children's individual needs, for example, to include passive children or to observe ongoing play sequences, so as to respond appropriately to the children involved. The study suggests that play tutoring in a group setting needs to be tailored to children's needs and should specifically aim to include withdrawn children actively, so that they can also profit from the intervention.

\section{Acknowledgements}

We appreciate the work of numerous students who collected data and rated videos. Special thanks go to Bettina Helmer, who was heavily involved in the development and implementation of the intervention and coding manuals.

\section{Funding}

The author(s) received no financial support for the research, authorship, and/or publication of this article.

\section{Note}

1. Examining the differential effects of play tutoring and time on social pretend play, it should be noted that no standardized results can be computed for models with random effects in Mplus as the variance of the dependent variables varies among between-level units. Only unstandardized effects are therefore reported for the model with random effects.

\section{ORCID iD}

Sonja Perren (iD https://orcid.org/0000-0002-7916-4037

\section{References}

Baumer S, Ferholt B and Lecusay R (2005) Promoting narrative competence through adult-child joint pretense: lessons from the Scandinavian educational practice of playworld. Cognitive Development 20(4): $576-590$.

Bergen D (2013) Does pretend play matter? Searching for evidence: comment on Lillard et al. (2013). Psychological Bulletin 139(1): 45-48.

Berk LE, Mann TD and Ogan AT (2006) Make-believe play: wellspring for development of self-regulation. In: Singer DG, Golinkoff RM and Hirsh-Pasek K (eds) Play = Learning: How Play Motivates and 
Enhances Children's Cognitive and Social-Emotional Growth. New York: Oxford University Press, pp. $74-100$.

Bodrova E (2008) Make-believe play versus academic skills: a Vygotskian approach to today's dilemma of early childhood education. European Early Childhood Education Research Journal 16(3): 357-369.

Bodrova E, Germeroth C and Leong DJ (2013) Play and self-regulation: lessons from Vygotsky. American Journal of Play 6(1): 111-123.

Christie JF (1983) The effects of play tutoring on young children's cognitive performance. The Journal of Educational Research 76(6): 326-330.

Copple C and Bredekamp S (2010) Developmentally Appropriate Practice in Early Childhood Programs Serving Children from Birth through Age 8. 3rd ed. Washington, DC: The National Association for the Education of Young Children.

Craig-Unkefer LA and Kaiser AP (2003) Increasing peer-directed social-communication skills of children enrolled in head start. Journal of Early Intervention 25(4): 229-247.

Elkonin DB (2005) The subject of our research: the developed form of play. Journal of Russian \& East European Psychology 43(1): 22-48.

Gmitrova V (2013) Teaching to play performing a main role - effective method of pretend play facilitation in preschool-age children. Early Child Development and Care 183(11): 1705-1719.

Gmitrová V and Gmitrov J (2003) The impact of teacher-directed and child-directed pretend play on cognitive competence in kindergarten children. Early Childhood Education Journal 30(4): 241-246.

Grady JS and Karraker K (2014) Do maternal warm and encouraging statements reduce shy toddlers' social reticence? Infant and Child Development 23(3): 295-303.

Hauser B (2013) Spielen: frühes Lernen in Familie, Krippe und Kindergarten. Stuttgart: Kohlhammer.

Henning A, Hofer T and Aschersleben G (2012) Erweiterte 'Theory of Mind'-skala Für 3- Bis 11-Jährige Kinder (Authorised German Translation of the Extended Theory-of-Mind Scale by Peterson, Wellman \& Slaughter, 2012). Saarbrücken: Saarland University.

Kristen S, Thoermer C, Hofer T, et al. (2006) Skalierung von 'Theory of Mind'-Aufgaben. Zeitschrift für Entwicklungspsychologie und Pädagogische Psychologie 38(4): 186-195.

Lang R, O'Reilly M, Rispoli M, et al. (2009) Review of interventions to increase functional and symbolic play in children with autism. Education and Training in Developmental Disabilities 44(4): 481-492.

Lillard AS, Lerner MD, Hopkins EJ, et al. (2013) The impact of pretend play on children's development: a review of the evidence. Psychological Bulletin 139(1): 1-34.

Little TD (2013) Longitudinal Structural Equation Modeling: Methodology in the Social Sciences. New York: The Guilford Press.

Nicolopoulou A, Barbosa De, Sa A, Ilgaz H, et al. (2010) Using the transformative power of play to educate hearts and minds: from Vygotsky to Vivian Paley and beyond. Mind, Culture, and Activity 17(1): 42-58.

Perren S (2007) SOCOMP (Self- and Other-Oriented Social Competences). Ein Fragebogen zur Erfassung von selbst- und fremdorientierten verhaltensbezogenen sozialen Kompetenzen. Zurich: Jacobs Center for Productive Youth Development, University of Zurich.

Perren S, Forrester-Knaus C and Alsaker F (2012) Self- and other-oriented social skills: differential associations with children's mental health and bullying roles. Journal for Educational Research Online/Journal Für Bildungsforschung Online 4(1): 99-123.

Perren S, Herrmann S, Iljuschin I, et al. (2017) Child-centred educational practice in different early education settings: associations with professionals' attitudes, self-efficacy, and professional background. Early Childhood Research Quarterly 38: 137-148.

Power TG (2011) Social play. In: Smith PK and Hart CH (eds) The Wiley-Blackwell Handbook of Childhood Social Development. Oxford: Wiley-Blackwell, pp. 455-471.

Qu L, Shen P, Chee YY, et al. (2015) Teachers' theory-of-mind coaching and children's executive function predict the training effect of sociodramatic play on children's Theory of Mind. Social Development 24(4): 716-733.

Smilansky S (1968) The Effects of Sociodramatic Play on Disadvantaged Preschool Children. Oxford: Wiley-Blackwell. 
Smilansky S and Shefatya L (1990) Facilitating Play: A Medium for Promoting Cognitive, Socio-Emotional and Academic Development in Young Children. Gaithersburg, MD: Psychosocial \& Educational Publications.

Smith PK (2010) Children and Play. Malden, MA: Wiley-Blackwell.

Sticca F, Goetz T, Nett U, et al. (2017) Short- and long-term effects of over-reporting of grades on academic self-concept and achievement. Journal of Educational Psychology 109: 842-854.

Trawick-Smith J and Dziurgot T (2011) 'Good-fit' teacher-child play interactions and the subsequent autonomous play of preschool children. Early Childhood Research Quarterly 26(1): 110-123.

Vygotsky LS (1978) Mind in Society: Development of Higher Psychological Processes. Cambridge, MA: Harvard University Press. 